\title{
An aza-cyclophane stacked in racemic columnar assemblies: whole-molecule disorder in a two-dimensional solid solution
}

\author{
M Zeller
}

Follow this and additional works at: https://ecommons.luc.edu/chemistry_facpubs

Part of the Chemistry Commons

Author Manuscript

This is a pre-publication author manuscript of the final, published article.

\section{Recommended Citation}

Zeller, M. An aza-cyclophane stacked in racemic columnar assemblies: whole-molecule disorder in a twodimensional solid solution. Acta Crystallographica Section B: Structural Science, Crystal Engineering and Materials, B65, : 223-229, 2009. Retrieved from Loyola eCommons, Chemistry: Faculty Publications and Other Works, http://dx.doi.org/10.1107/S0108768109002134

This Article is brought to you for free and open access by the Faculty Publications and Other Works by Department at Loyola eCommons. It has been accepted for inclusion in Chemistry: Faculty Publications and Other Works by an authorized administrator of Loyola eCommons. For more information, please contact ecommons@luc.edu. cc) (i) $\Theta$

This work is licensed under a Creative Commons Attribution-Noncommercial-No Derivative Works 3.0 License. (c) International Union of Crystallography, 2009. 


\title{
An aza-cyclophane stacked in racemic columnar assemblies: Whole molecular disorder in a 2D solid solution
}

\author{
Matthias Zeller, ${ }^{*}$ Marlon R Lutz Jr., $\$$ Daniel P. Becker ${ }^{* \$}$ \\ \# Youngstown State University, Department of Chemistry, 1 University Plaza, \\ Youngstown Ohio 44555-3663, USA \\ \$ Department of Chemistry, Loyola University, 6525 North Sheridan Road, Chicago, \\ IL 60626
}

Synopsis 10 -membered $\mathrm{N}$-acetyl macrocyclic amide $\mathbf{2}$ crystallizes as a solid solution of racemic columnar assemblies comprised of alternating enantiomers in a stacked-cup array, each as a chloroform monosolvate, but with a random distribution of the columns within the crystal leading to whole molecule disorder within the crystal.

\begin{abstract}
The oxime derivative of [1.1.1]cyclophane cyclotriveratrylene (CTV) was ring expanded utilizing a Beckmann rearrangement to provide a 10-membered $\mathrm{N}$-acetyl macrocyclic amide that crystallizes as a chloroform monosolvate in columnar assemblies manifesting an unusual disorder within the crystal. Columns comprising this structure consist of infinite columnar assemblies of alternating D and $\mathrm{L}$ enantiomers and therefore necessarily comprise a racemate, yet the chiralities of individual molecules in adjacent columns are independent of one another leading to the overall formation of a 2D-solid solution. The random arrangement of the columns within the structure leads to emergence of a crystallographic mirror plane not reflected by the molecular symmetry, to a change of symmetry from Pna2 ${ }_{1}$ to Pnma and to whole molecule disorder of the bowl-shaped molecules within the columns.
\end{abstract}

Keywords: cyclotriveratrylene; CTV; solid solution; whole molecule disorder;
columnar assemblies, host-guest; Beckmann rearrangement 1. Origin of the material

Cyclotriveratrylene (CTV) (Collet, 1987) and its [1.1.1]cyclophane congeners in their rigid crown conformation are unique bowl-shaped molecules that serve as supramolecular scaffolds, and they can function as molecular receptors utilizing their concave face for the recognition of suitable small molecules (Collet, 1996; Burlinson \& Ripmeester, 1984; Steed et al., 1996). Our interest in the crown-saddle conformational interconversion of CTV derivatives including CTV oxime 1 (Lutz, 2007a) led us to explore the Beckman rearrangement of this molecule (Lutz et al. 2007b). The Beckmann ring expansion (Scheme 1, 
Experimental) leads to an amide-containing concave" "pinched-bowl" shaped, planar chiral azacyclophane with potential applications in host guest chemistry, so we pursued the crystal structure of the $\mathrm{N}$-acetyl macrocyclic amide, 2.

\section{Experimental}

\subsection{Sample preparation}

5-Acetyl-2,3,8,9,13,14-hexamethoxy-11,16-dihydrotribenzo[b,e,h]azecin-6(5H)-one $\quad 2$,

Method A. To a solution of cyclotriveratrylene (CTV) oxime (Lutz et al., 2007a) (1.00 g, $2.08 \mathrm{mmol})$ as a ca. 1:1 mixture of crown and saddle conformers in pyridine $(2.1 \mathrm{ml})$ at room temperature under an atmosphere of argon was added acetyl chloride $(0.246 \mathrm{~g}, 26.1 \mathrm{mmol})$ dropwise via syringe. After $21 \mathrm{~h}$ at room temperature the orange-red reaction suspension was diluted with methylene chloride $(20 \mathrm{~mL})$ and washed successively with $1 \mathrm{~N} \mathrm{HCl}(2 \times 30 \mathrm{~mL})$, saturated aqueous $\mathrm{NaHCO}_{3}(20 \mathrm{~mL})$, brine, and then dried over sodium sulfate. Concentration gave the desired CTV oxime O-acetate intermediate (1.03 g, 95.1\%) as a light orange foam which was a ca. 1:1 mixture of saddle and crown conformers based on TLC. To a $50 \mathrm{~mL}$ Pyrex round bottom flask that was flame-dried and charged with argon was added the cyclotriveratrylene oxime O-acetate $(113 \mathrm{mg}, 0.217 \mathrm{mmol})$ and $21.7 \mathrm{~mL}$ of $t$-butanol. This mixture was deoxygenated by placing the flask in a sonicator for 20 minutes with an argon purge. Under an argon atmosphere, the reaction mixture was then irradiated with a $400 \mathrm{~W}$ mercury lamp at room temperature for three hours. Removal of solvent under reduced pressure gave $115 \mathrm{mg}$ of an orange residue. Purification via chromatography gave the Beckmann amide $\mathrm{N}$-acetate product 2 as a colorless solid (20.4 mg, 18\%). Crystals were grown by diluting $20 \mathrm{mg}$ of 2 in $0.5 \mathrm{ml} \mathrm{CDCl}_{3}$ with $5.0 \mathrm{~mL}$ dichloromethane and $1.0 \mathrm{~mL}$ hexane: $\mathrm{mp} 116-118^{\circ} \mathrm{C}$ (sintering only) following by melting at $132-135^{\circ} \mathrm{C}$ and subsequent effervescence, then resolidification at $140^{\circ} \mathrm{C}$; a second melting point was then observed at 175-178 ${ }^{\circ} \mathrm{C} .{ }^{1} \mathrm{H}$ NMR $\left(\mathrm{CDCl}_{3}\right): \delta 8.32\left(1 \mathrm{H}, \mathrm{s}, \mathrm{C}^{\mathrm{HCl}}{ }_{3}\right), 6.84(1 \mathrm{H}, \mathrm{s}), 6.82(1 \mathrm{H}, \mathrm{s}), 6.62(1 \mathrm{H}, \mathrm{s})$, $6.59(2 \mathrm{H}, \mathrm{s}), 6.41(1 \mathrm{H}, \mathrm{s}), 4.25(1 \mathrm{H}, \mathrm{d}, 14.7 \mathrm{~Hz}), 4.01(1 \mathrm{H}, \mathrm{s}, 14.7 \mathrm{~Hz}), 3.92(3 \mathrm{H}, \mathrm{s}), 3.90(3 \mathrm{H}$, s), $3.77(3 \mathrm{H}, \mathrm{s}), 3.75(3 \mathrm{H}, \mathrm{s}), 3.73(3 \mathrm{H}, \mathrm{s}), 3.73(3 \mathrm{H}, \mathrm{s}), 3.72(3 \mathrm{H}, \mathrm{s}), 3.62(1 \mathrm{H}, \mathrm{d}, 14.7 \mathrm{~Hz})$, 3.47 (1H, d, $14.7 \mathrm{~Hz}), 2.74$ (3H, s). ${ }^{1} \mathrm{H}$ NMR (d6-DMSO): $\delta 7.15(1 \mathrm{H}, \mathrm{s}), 7.13(1 \mathrm{H}, \mathrm{s}), 6.98$ $(1 \mathrm{H}, \mathrm{s}), 6.94(1 \mathrm{H}, \mathrm{s}), 6.74(1 \mathrm{H}, \mathrm{s}), 6.72(1 \mathrm{H}, \mathrm{s}) 4.05(1 \mathrm{H}, \mathrm{d}, 14.0 \mathrm{~Hz}), 3.87(1 \mathrm{H}, \mathrm{d}, 14.0 \mathrm{~Hz})$, $3.79(3 \mathrm{H}, \mathrm{s}), 3.78(3 \mathrm{H}, \mathrm{s}), 3.63(3 \mathrm{H}, \mathrm{s}), 3.62(3 \mathrm{H}, \mathrm{s}), 3.61(3 \mathrm{H}, \mathrm{s}), 3.60(3 \mathrm{H}, \mathrm{s}), 3.42(2 \mathrm{H}, \mathrm{d}$, $14.6 \mathrm{~Hz}), 2.70(3 \mathrm{H}, \mathrm{s})$.

5-Acetyl-2,3,8,9,13,14-hexamethoxy-11,16-dihydrotribenzo[b,e,h]azecin-6(5H)-one $\quad \mathbf{2}$, Method B. To a solution of 2,3,8,9,13,14-hexamethoxy-11,16-dihydrotribenzo[b,e,h]-azecin6(5H)-one 3 (100 mg, $0.209 \mathrm{mmol}$; Lutz et al., 2008), in pyridine (1.0 mL) was added acetic 
anhydride $(0.5 \mathrm{~mL})$, and the mixture was heated to reflux for 2 hours. After cooling to room temperature the reaction mixture was diluted with deionized water $(18 \mathrm{~mL})$ to give a slurry which was extracted with ethyl acetate $(3 \times 5 \mathrm{~mL})$. The combined organic layers were successively washed with $1 \mathrm{M}$ aqueous $\mathrm{HCl}(2 \times 10 \mathrm{~mL})$, deionized water $(1 \times 10 \mathrm{~mL})$, and brine $(1 \times 10 \mathrm{~mL})$, and dried over sodium sulfate. Concentration under reduced pressure afforded $121 \mathrm{mg}$ of a golden yellow glass. Column chromatography eluting with a gradient ( $100 \% \mathrm{CH}_{2} \mathrm{Cl}_{2}$ to $35 / 65$ diethyl ether $/ \mathrm{CH}_{2} \mathrm{Cl}_{2}$ ) with a $28: 1$ loading ratio of silica gel afforded $\mathrm{N}$-acyl amide 2 (103 mg, 94.6\%). Crystallization from either $\mathrm{CDCl}_{3} / \mathrm{CH}_{2} \mathrm{Cl}_{2} /$ hexane, $\mathrm{CHCl}_{3} / \mathrm{CH}_{2} \mathrm{Cl}_{2} /$ hexane or $\mathrm{CHCl}_{3} /$ hexane gave crystals that were identical by ${ }^{1} \mathrm{H}$ NMR to material prepared via Method A, and with identical melting characteristics as described above.

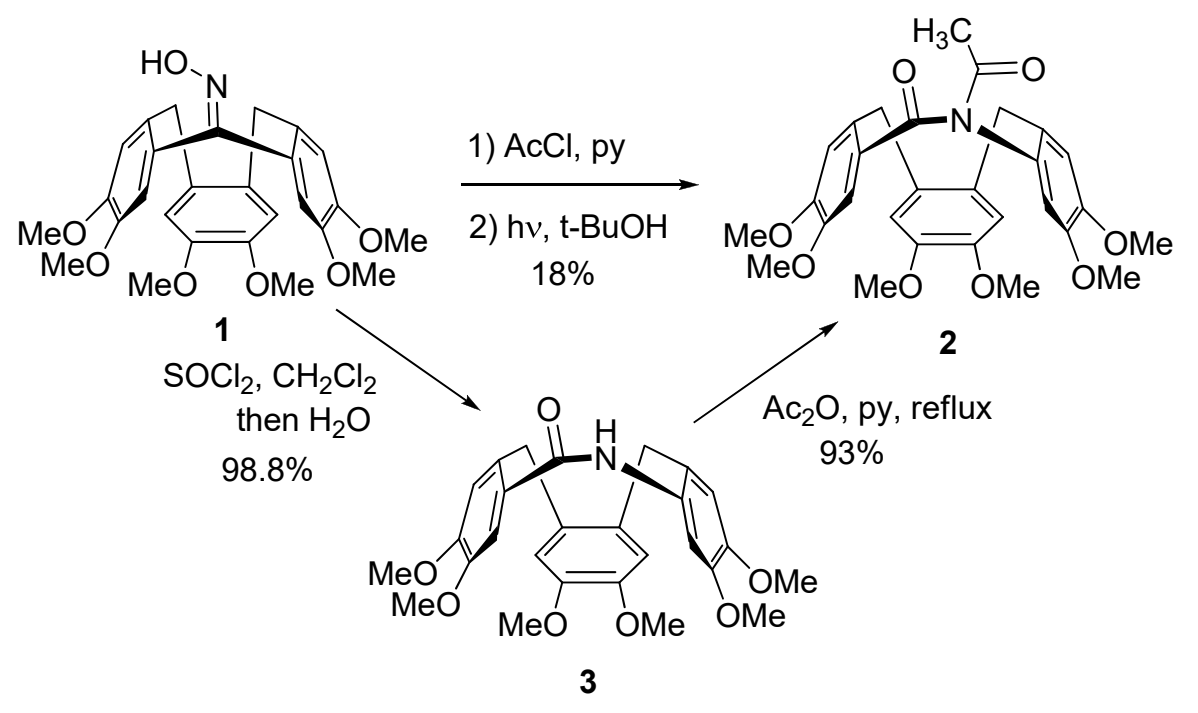

\subsection{Single Crystal Data Collections}

\subsubsection{Experimental Strategy and Data Collection}

Single crystal X-Ray data were collected on a Bruker AXS Smart Apex diffractometer equipped with a Kryoflex cooling system using monochromatic Mo Ka radiation with the omega scan technique. A clear and perfectly transparent light yellow plate without any obvious breaks or discontinuities was selected and mounted with help of a small amount of mineral oil onto a MiTeGen MicroMesh mount with $25 \mu \mathrm{m}$ mesh size.

\subsubsection{Crystal Structure Refinement}

The molecule - while being itself planar chiral and not mirror symmetric - is located in the solid state on a crystallographic mirror plane, thus superimposing image and mirror image of 
the molecule in a 1:1 ratio atop of each other. The main difference in steric demand between the two enantiomers is found at the $\mathrm{N}$-acteylamide part of the macrocylce. The different steric demands of the $\mathrm{N}$-acetyl versus the keto groups most atoms induce a noticeable shift of most of the atoms of the molecule when compared to their counterparts in the other enantiomer and only the dimethoxy benzene unit furthest away from the $\mathrm{N}$-acteylamide exhibits exact mirror symmetry. The remainder of the molecule is disordered over two alternative sets of positions. The chloroform solvate molecule, also located on the mirror plane, shows no disorder. The positions of all atoms in both of the slightly shifted moieties are sufficiently well defined to allow for a refinement without any positional or similarity restraints. Thermal parameters of disordered atoms are also well defined. Three pairs of mirror related atoms with rather large overlap (C5 \& C5A, C12 \& C12A and C13 and C13A) were constrained to have identical ADPs, but no other con- or restraints were applied for any other atom in the structure. Hydrogen atoms were added in calculated positions with $\mathrm{C}-\mathrm{H}$ distances of $0.95,0.99$ and 0.98 $\AA$ for aromatic, methylene and methyl $\mathrm{H}$ atoms, respectively, and were refined with $\mathrm{U}_{\text {iso }}(\mathrm{H})=$ $\mathrm{x} \mathrm{U}_{\mathrm{eq}}(\mathrm{C})\left(\mathrm{x}=1.2\right.$ for $\mathrm{C}-\mathrm{H}$ and $\mathrm{CH}_{2}, 1.5$ for $\left.\mathrm{CH}_{3}\right)$.

The structure was also tentatively refined under omission of the mirror plane perpendicular to the b-axis in the alternative space group P $n a 2_{1}$. The refinement resulted, however, in a structure showing the same disorder as in Pnma with a 1:1 ratio for both moieties ${ }^{1}$. Inclusion of racemic twinning did not improve the structural model and the batch scale factor refined to 0.41(19).

\subsection{Differential Scanning Calorimetry (DSC), Thermogravimetric Analysis (TGA) and NMR spectroscopy}

DSC data were collected on a 2910 Differential Scanning Calorimeter, and TGA data were collected on a 2050 Thermographimetric Analyzer. Both instruments are from TA Instruments. DSC data were collected in sealed, TGA data in open aluminum pans. Heating rates were between 0.5 and $5^{\circ} \mathrm{C}$ per minute. The DSC of $\mathrm{N}$-acetyl derivative 2 reveals two separate endothermic events. The first endotherm begins at $132^{\circ} \mathrm{C}$, consistent with melting of the crystal, observed in an open capillary using an Electrothermal Mel-Temp at $132-135^{\circ} \mathrm{C}$, and then reaches the crest of a large heat influx at $148^{\circ} \mathrm{C}$, consistent with the subsequent loss of $\mathrm{CHCl}_{3}$ observed as effervescence in the open capillary. The second endotherm in the DSC begins at $178^{\circ} \mathrm{C}$ and reaches a maximum at $189^{\circ} \mathrm{C}$, consistent with the second melting point observed at $175-178^{\circ} \mathrm{C}$ in the open capillary after the sample had resolidified following the

\footnotetext{
${ }^{1}$ Refined ratios in Pna2 $2_{1}$ fluctuated a few percent around 0.50 (e.g. 0.535(5):0.465(5)), depending on the exact model and set of restraints that needed to be used due to the high correlation of parameters in Pna2 ${ }_{1}$.
} 
initial melting and effervescence. In the TGA, a weight loss of $18.6 \%$ was observed near 140 ${ }^{\circ} \mathrm{C}$, consistent with loss of exactly one equivalent of $\mathrm{CHCl}_{3}$ per molecule of $\mathbf{2}$, immediately following the initial melting of the crystal at $132-135^{\circ} \mathrm{C}$. The $1: 1$ stoichiometry of the chloroform solvate is also consistent with the integration of the ${ }^{1} \mathrm{H}$ NMR peak at $8.32 \mathrm{ppm}$ in $\mathrm{d}_{6}$-DMSO as listed in the Experimental Section above. NMR data were collected on a Varian Gemini-300 NMR spectrometer at $300 \mathrm{MHz}$. Spectra and more details of TGA, DSC and NMR spectra are given in the supporting material.

\section{Results and Discussion}

\subsection{The Basic Structure}

Recrystallisation of $\mathbf{2}$ from chloroform yielded well-formed crystals suitable for single crystal diffraction. After data collection, systematic absences indicated the centrosymmetric and achiral space group Pnma. Initial structure solution and refinement in this setting, however, did not reveal a well-defined single molecule. Only a solvate chloroform molecule and one dimethoxy benzene unit were readily discernable; the remainder of the structure appeared severely disordered. A close analysis of the data pointed toward whole molecule disorder of the organic molecule, which - while being itself not mirror symmetric - is located in the solid state on a crystallographic mirror plane. The whole molecule disorder of the structure seems to be possible because the two enantiomers are coincidently spatially sufficiently similar to be interchangeable within the crystal, as will be described in detail in the following sections.

Refinement of the structure in Pnma under consideration of the disorder was then straightforward (see experimental refinement section). An ortep style plot of one single molecule is given in Figure 1, and a view of the expanded asymmetric unit showing the disorder is shown in Figure 2 (which is also available as an enhanced interactive figure at http://submission.iucr.org/jtkt/serve/z/YpTnfhHJJnjiQCre/zz0000/0/).

A substantial portion of the molecule does actually exhibit approximate chemical mirror symmetry. Within the backbone - comprised of the substituted aromatic rings, the methylene bridges and the $\mathrm{C}-\mathrm{N}$ unit of the amide moiety - the symmetry is only broken by the positions of the nitrogen and carbon atoms of the amide bridge. The steric demands of the two alternative orientations are very similar with the only significant differences being introduced by the functionality of the $\mathrm{N}$-acetyl amide unit. Application of the mirror plane on the molecule as a whole inverts this asymmetric group and converts its $\mathrm{N}$-acetyl unit into the nearly isosteric macrocyclic amide keto moiety. The acetyl methyl groups, which are located almost on the mirror plane, do not introduce any significant differences in spatial demand for 
the two orientations. The acetyl oxygen atom, however, has a higher steric demand than its counterpart on the other side of the molecule - the oxygen atom of the lactam keto group. When inverted, the acetyl group extends outwards further by about the length of the double bond of the acetyl $\mathrm{C}=\mathrm{O}$ group (i.e. ca. $1.2 \AA$ ). In order for both orientations of the molecule to still fit the same spatial region, each of the mirror-imaged $\mathrm{N}$-acetyl amide groups has to shift by about half this distance towards the mirror plane. This shift of the atoms positioned away from the ideal mirror symmetry is most pronounced for the section of the molecule surrounding the $\mathrm{N}$-acetyl amide group and slowly coalesces when reaching the opposing end of the molecule. Thus the dimethoxybenzene unit furthest away from the $\mathrm{N}$-acetylamide exhibits exact mirror symmetry, as does the solvate chloroform molecule (Figure 2).

The acyl and keto functionalities of the $\mathrm{N}$-acyl amide unit in the structure are coplanar and the unit as a whole comprises a conjugated imide group. The rms deviation of its constituent atoms - the $\mathrm{N}$-acyl lactam atoms and the ipso carbon atoms of the adjacent phenyl rings from its least square plane is only 0.113(4)Á with the largest individual deviation being just $0.170(4) \hat{A}$ for the lactam oxygen atom O4. The plane of the N-acyl lactam group is basically perpendicular to those of the adjacent phenyl rings with dihedral angles of 82.7(3) and $88.1(3)^{\circ}$, respectively.

The 10-membered ring of compound $\mathbf{2}$ as a whole presents a convex cavity in the shape of a "pinched bowl". In the case of compound 2 the void within the bowl is filled by the N-acyllactam group of a neighbouring molecule and part of a chloroform molecule that both reach into this cavity (Figure 3 ) forming stacked columnar assemblies along the a-axis of the unit cell. The stacking of conical molecules in smectic assemblies is of interest in the preparation of liquid crystals (Sawamuru et al. 2002, Kato et al. 2006). Native CTV typically forms crystalline clathrates with small molecules wherein the guests are located in channels between pillars of stacked CTV molecules (Steed et al. 1996, Hyatt et al. 1980). Extended-arm cavitands derived from CTV may also form stacked pillars of the bowl-shaped molecules (Hardie et al. 2004). Hardie has specifically observed racemic CTV-derived host molecules with alternating chiralities stacked within a column in the racemic crystal (Ahmad et al. 2006).

CTV and its derivatives may undergo in solution an interconversion between the crown conformer such as found here in the solid state and the alternative saddle conformer (Zimmermann et al. 2004). NMR spectra of $\mathbf{2}$ in $\mathrm{CDCl}_{3}$, however, indicate no such behaviour here. Confirming the presence of the rigid crown conformation, the ${ }^{1} \mathrm{H}$ NMR shows, in addition to six unique aryl $\mathrm{C}-\mathrm{H}$ protons and six unique methoxy singlets, two $\mathrm{AB}$ quartets between $3.4-4.3 \mathrm{ppm}$ with strong geminal coupling of $14.7 \mathrm{~Hz}$. The acetyl singlet resonates at $2.74 \mathrm{ppm}$, deshielded ca. $0.5 \mathrm{ppm}$ downfield from a typical imide methyl group due to the 
anisotropy induced by the macrocyclic amide carbonyl. Amide rotamers are observed in $\mathrm{CDCl}_{3}$ in a ratio of $4: 1$, presumably favouring the syn coplanar conformation over the anti conformation, whereas amide rotamers are not observed in the more polar $\mathrm{d}_{6}$-DMSO solvent. The crystal structure confirms the syn coplanar conformation of the acyl moiety in the solid, placing the methyl group within the deshielding cone of the amide carbonyl, at least in the crystalline state. This overall rigidity of $\mathbf{2}$ may be attributed to the lactam linker in $\mathbf{2}$ which is significantly more rigid than its carbocyclic [2.1.1] orthocyclophane analogue recently prepared by Yamato (2001), which exists as an equilibrium mixture of crown, syn-saddle and anti-saddle conformers. Yamato et al. reported the crystal structure of the highly flexible antisaddle conformer - not of the rigid "bowl-shaped" crown conformer as observed for macrocycle 2 .

The DSC of N-acetyl derivative 2 reveals two separate endothermic events. The first endotherm occurs at $148{ }^{\circ} \mathrm{C}$ and is consistent with melting of the crystal and concomitant loss of $\mathrm{CHCl}_{3}$. A second endotherm at $189^{\circ} \mathrm{C}$ is consistent with the second melting point observed by melting point determination in a capillary. Weight loss near $140{ }^{\circ} \mathrm{C}$ observed in the TGA is consistent with the loss of one molecule of $\mathrm{CHCl}_{3}$ per molecule of 2 from the melted crystal. The sintering that we had observed visually in the capillary melting point measurement at 116-118 ${ }^{\circ} \mathrm{C}$, which we considered may reflect a possible transition to a liquid crystalline phase, was not apparent in the DSC. Consistent with the visual melting point, the effervescence due to boiling off of the chloroform occurs as the crystal melts, as the chloroform is released from the crystal lattice, and thus does not appear as a separate endotherm in the DSC. We considered that we might observe an exotherm for resolidification of the material after the initial melting plus effervescence, but the exotherm is presumably obscured by the more energetic endotherm from loss of the solvent.

\subsection{A 2D Solid Solution Racemate Built of Infinite Racemic Columnar Assemblies}

While the structure of the individual molecule as well as the apparent disorder within the crystal initially piqued our interest, we then turned our attention to the unique arrangement of the individual units within the crystal structure as a whole. The space group that compound 2 crystallizes in is centrosymmetric. Asymmetrically substituted calixarene-like molecules such as $\mathbf{2}$ are however planar chiral and thus, averaged over the crystal as a whole, the compound must thus be a racemate with a one-to-one ratio of enantiomers. The vast majority of crystalline racemic mixtures are comprised of a racemic compound where both enantiomers in the unit cell are related by a crystallographic inversion or mirror symmetry. Racemates may also be conglomerates (Kondepudi et al., 2005), containing pure crystals of the two 
enantiomers mechanically intermixed with one another as in the famous case of sodium ammonium tartrate manually resolved by Pasteur. Lastly, crystalline racemates may be solid solutions, with random dispersion of the two enantiomers throughout the crystal (Jacques et al., 1981). Solid solutions are rare (Huang et al., 2006), but it has been suggested that chiral molecules with a pseudo-element of symmetry are more likely to crystallize as solid solutions (Chion et al., 1978). Similarly, pseudo-symmetric diastereomers that are similar in shape to a sufficient extent are more likely to crystallize as solid solutions (Barabas, 2000). Strictly speaking, however, crystalline compound $\mathbf{2}$ does not belong to any of these three classes. As we will describe in detail in the following sections it rather seems to have some properties of a classical racemate with crystallographic inversion symmetry within individual columns comprised of molecules of alternating chirality (2D), yet it is comprised of a solid solution with a statistical distribution of the two enantiomers between adjacent parallel columns.

The individual molecules of $\mathbf{2}$ are azacyclophane derivatives containing a convex cavity formed by the three constituent phenyl moieties. The cavity is in turn filled by the N-acyllactam group of a neighbouring molecule and part of a solvate chloroform molecule. Neighbouring molecules along the a-axis are in this way interlocked with one another and form infinite chains or columnar assemblies throughout the crystal. The connection between adjacent molecules along theses chains is - in part - facilitated by a number of medium strength intermolecular interactions. There are no acidic hydrogen atoms (aside of the chloroform $\mathrm{C}-\mathrm{H}$ ), so there are no classical hydrogen bonds. There are, however, a range of weak non-classical C-H...O hydrogen bonds and also several C-H $\cdots \pi$ contacts within the cavity. While these forces are individually relatively weak, in the absence of other stronger interactions they constitute a large part of the attractive forces between neighbouring molecules (vande Velde et al. 2004). The exact nature of these interactions is complicated by the whole molecule disorder. A close analysis of all potential interactions within the chains along the axis, however, reveals that there is only one rational arrangement of the disordered molecules within each chain, and that this arrangement consists of alternating molecules with opposite chirality but with the $\mathrm{N}$-acyl-amide units all pointing towards the same side of the chain as shown in Figure 4. This is most easily shown for the C-H...O contacts (Table 2) which within each chain dominate the interactions between neighbouring molecules: The more protruding acyl oxygen atom $\mathrm{O} 5$ induces via a $\mathrm{C}-\mathrm{H}$... O bond a slight rotation of the neighbouring molecule around its centre of gravity. This rotation allows its methoxy group on the other side of the molecule to approach the lactam keto oxygen atom O4 of the other molecule to form two other medium strong $\mathrm{C}-\mathrm{H} \ldots \mathrm{O} \mathrm{O}$ bonds. For an arrangement with alternating $\mathrm{D}$ and $\mathrm{L}$ molecules as in Figure 4 the most prominent $\mathrm{C}-\mathrm{H} \ldots \mathrm{O}$ interactions that contribute to the binding within each cavity have H...O distances of 2.36 and $2.65 \AA$ (for 
C13A-H13E...O $5^{\text {viii }}$ and $\mathrm{C} 13-\mathrm{H} 13 \mathrm{C} \ldots \mathrm{O} 4^{\text {viii }}$, respectively) (Table 2). This is well within the usual range found for this kind of weak hydrogen bond-like interaction. Placing two molecules with the same sense of rotation in adjacent positions along the chains, however, would enforce a very short $\mathrm{C}-\mathrm{H} \ldots \mathrm{O}$ contact of $2.10 \AA$ for $\mathrm{C} 13-\mathrm{H} 13 \mathrm{C} \ldots \mathrm{O} 5^{\mathrm{ix}}$ and a second main $\mathrm{C}-\mathrm{H} \cdots \mathrm{O}$ contact, $\mathrm{C} 13 \mathrm{~A}-\mathrm{H} 13 \mathrm{E} \ldots \mathrm{O} 4^{\mathrm{ix}}$, would be stretched to $2.95 \AA$. Furthermore the assigned arrangement with alternate $\mathrm{D}$ and $\mathrm{L}$ molecules also avoids a close $\mathrm{H} \cdots \mathrm{H}$ contact of $1.94 \AA$ between $\mathrm{H} 18 \mathrm{C}$ and $\mathrm{H} 13 \mathrm{C}$ (the contact between $\mathrm{H} 18 \mathrm{C}$ and $\mathrm{H} 13 \mathrm{E}$ is $2.411 \AA$ ). A similar analysis for the $\mathrm{C}-\mathrm{H} \cdots \pi$ contacts leads to the same conclusion: that enantiomers must alternate within a given column (Table 2$)^{2}$

Barring a discontinuity along the chain each column parallel to the a-axis thus consists of infinite chains of alternating D and $\mathrm{L}$ molecules with all N-acyl-lactam units within one chain pointing to the same side of the chain, and with all oxygen atoms consistently $\mathrm{C}-\mathrm{H}$...O binding to the same methoxy group (C13-H13C and C14-H14a to O4 ${ }^{\text {viii }}$ and C13A-H13E to O5 ${ }^{\text {viii }}$ ). The next molecule in the chain is, however, mirror imaged: it is predicted by the exact application of the "a" glide plane of the Pnma cell. This means each column is a perfect racemate by itself with an infinite D-L-D-L-D-L motif.

Do neighbouring chains influence each other's arrangement of the D and L molecules? Any D-L arrangement of neighbouring chains that is not random at least within large domains of the crystal would have to result in the disappearance of the disorder and thus of the mirror plane in the Pnma setting. This would lead either to a change of the cell parameters by a transformation of point group to translational symmetry - a possibility that can be readily rejected on the basis of the diffraction patterns - or to the formation of a crystal in the lower symmetry and non-centrosymmetric space group P $n a 2_{1}$. Refinement in this space groups led, however - even under consideration of racemic twinning - to the same type of disorder as observed in Pnma. An analysis of the packing of neighbouring chains leads to a similar conclusion. Neighbouring chains created by the $\mathrm{n}$ glide plane are pointing in opposite directions and are interlocked with each other via the extending methoxy groups and the solvate chloroform molecules. One thus would expect them to be unable to shift against each other in the solid state, as this would involve shifting an entire column through the whole

\footnotetext{
${ }^{2}$ This analysis is nonetheless complicated by the disorder of the molecules and one runs the risk that inaccurately positioned atoms might lead to erroneous conclusions. The atom positions were, however, refined without any positional restraints. Further, based on bond distance considerations no reasonable reassignment of atom positions to the other moiety is possible.
} 
crystal. Any alignment of either D or L molecules in neighbouring chains thus has to be established throughout the crystallization process. Unlike within a given chain there seems to be no preferential set of intermolecular forces between neighbouring columns. This leaves a random arrangement of chains with respect to each other as the only possible arrangement. In this sense the crystal may be characterized as a solid solution of chiral molecules comprised of racemic columnar assemblies. In planes perpendicular to the a-axis the distribution of $\mathrm{D}$ and $\mathrm{L}$ molecules thus appears to be random, and these planes thus each form a layer that could be viewed as a two dimensional (2D) solid solution. Along the a-axis, however, the enantiomers are alternating within each chain as in a classic racemic crystal where adjacent enantiomers in the unit cell are related by crystallographic inversion or mirror symmetry.

\section{Summary and Conclusions}

Beckmann ring-expanded CTV derived $\mathrm{N}$-acetyl amide $\mathbf{2}$ was crystallized as a chloroform monosolvate as a 2D-solid solution of racemic columnar assemblies comprised of alternating enantiomers in a stacked-cup array, but with a random distribution of the columns within the crystal leading to whole molecule disorder within the crystal. DSC and TGA analysis are consistent with open-capillary melting point measurements of the crystalline solvate and expulsion of the chloroform solvent, followed by resolidification and a second melting event.

\section{Supporting Materials}

Figures of ${ }^{1} \mathrm{H}$ NMR spectra and DSC and TGA data of 2 are given in the supplementary material.

Figure 1 Ortep-style representation of one symmetry expanded molecule. Only one of the two possible molecules created by the whole molecule disorder is shown and the chloroform solvate molecule is omitted for clarity. Symmetry operator i: $\mathrm{x}, 0.5-\mathrm{y}, \mathrm{z}$, the probability of the thermal ellipsoids is set to $50 \%, \mathrm{H}$ atoms are drawn at fixed arbitrary radii. 


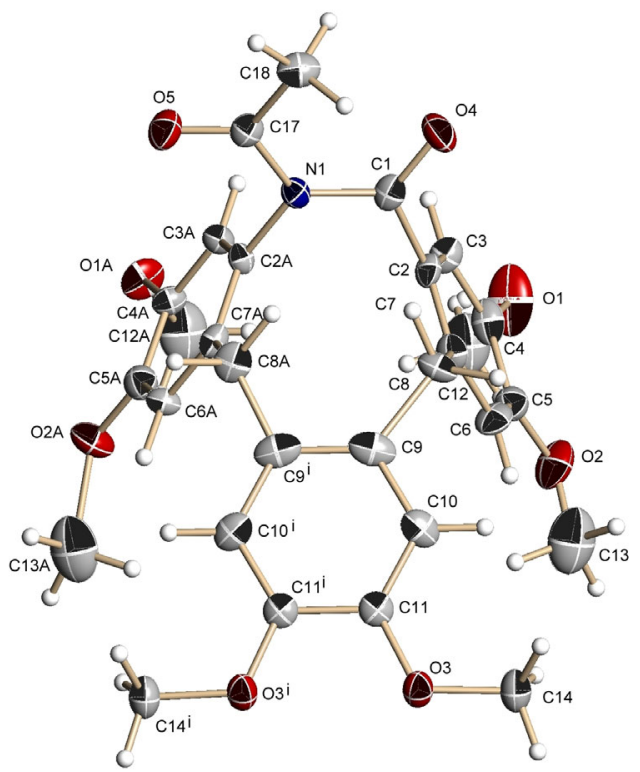

Figure 2 Ball-and-stick-style enhanced figure showing the whole molecule disorder. To view the interactive figure online access http://submission.iucr.org/jtkt/serve/z/YpTnfhHJJnjiQCre/zz0000/0/. The chloroform solvate molecule is omitted for clarity. Carbon atoms belonging to the second orientation of the molecule (created by the crystallographic mirror operation) are drawn in a lighter shade of gray; bonds within this moiety are indicated by dashed green lines. Hydrogen atoms are omitted for clarity.

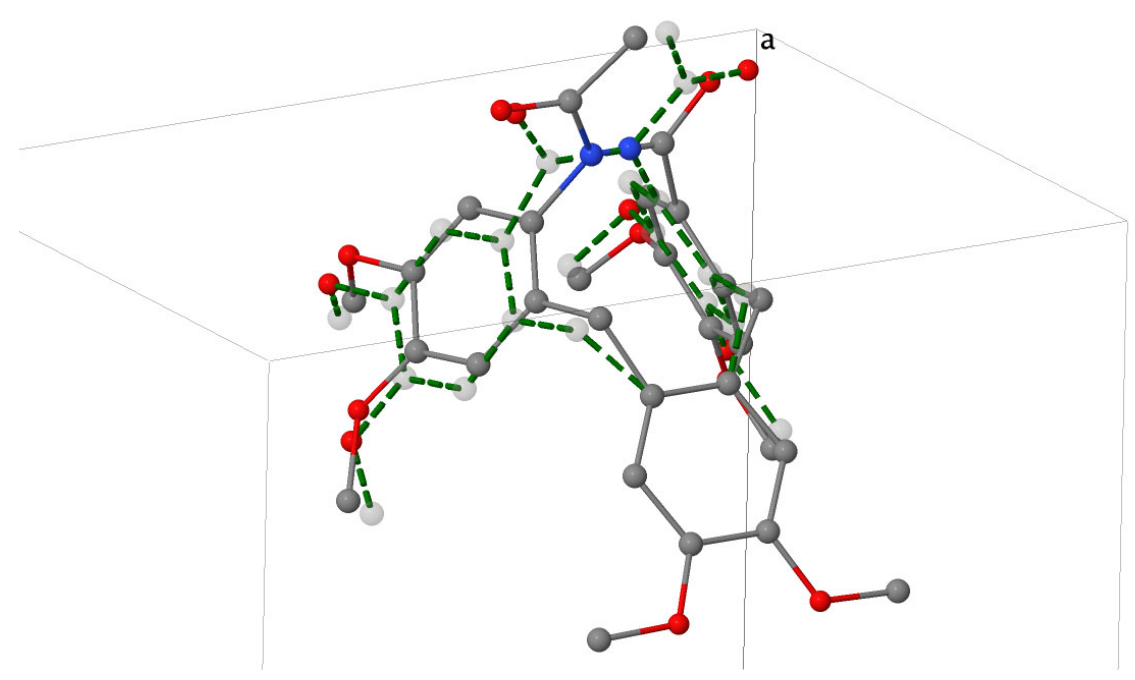

Figure 3 Spacefill representation showing how the N-acyl-lactam moiety (purple) and the solvate chloroform molecule reach into the conical cavity of a neighbouring molecule (light blue). For better visibility the "spacefill radii" of the atoms are set to $70 \%$ of the respective van der Waals radii. Both alternative orientations of the molecule are displayed. The view is perpendicular to the a-axis and down the b-c diagonal of the unit cell. 


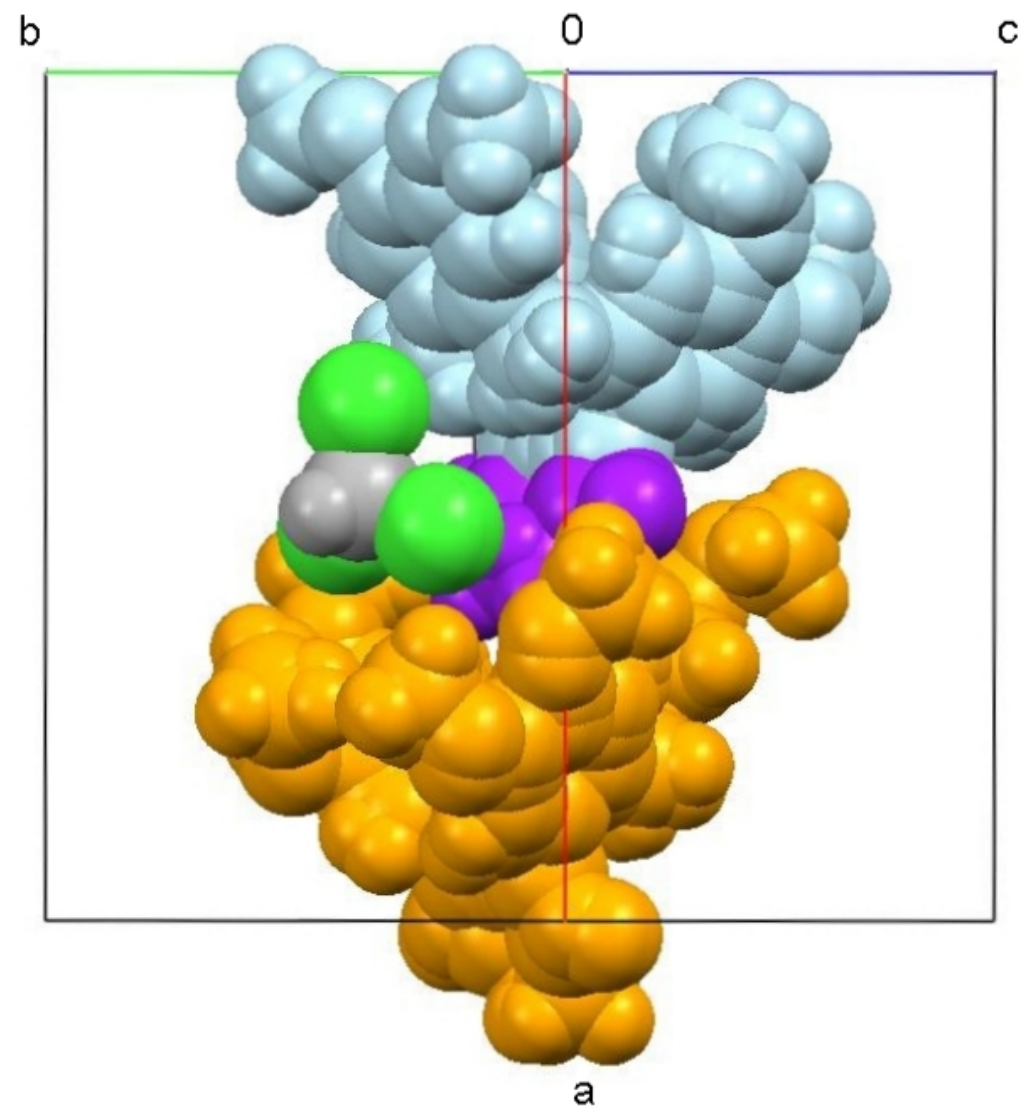

Figure 4 Ortep style representation showing of a section of the columnar assembly along the a-axis showing the intermolecular interactions. $\mathrm{C}-\mathrm{H} \cdots \mathrm{O}$ and $\mathrm{C}-\mathrm{H} \cdots \mathrm{C}$ interactions are represented by light blue dotted lines. Red dotted lines represent $\mathrm{C}-\mathrm{H} \cdots \pi$ bonds towards the centroid of an aromatic ring (displayed as a dark blue sphere). Probability of the thermal ellipsoids is at $50 \%, \mathrm{H}$ atoms are drawn as capped rods. View down the c-axis (left) and b-axis (right). 

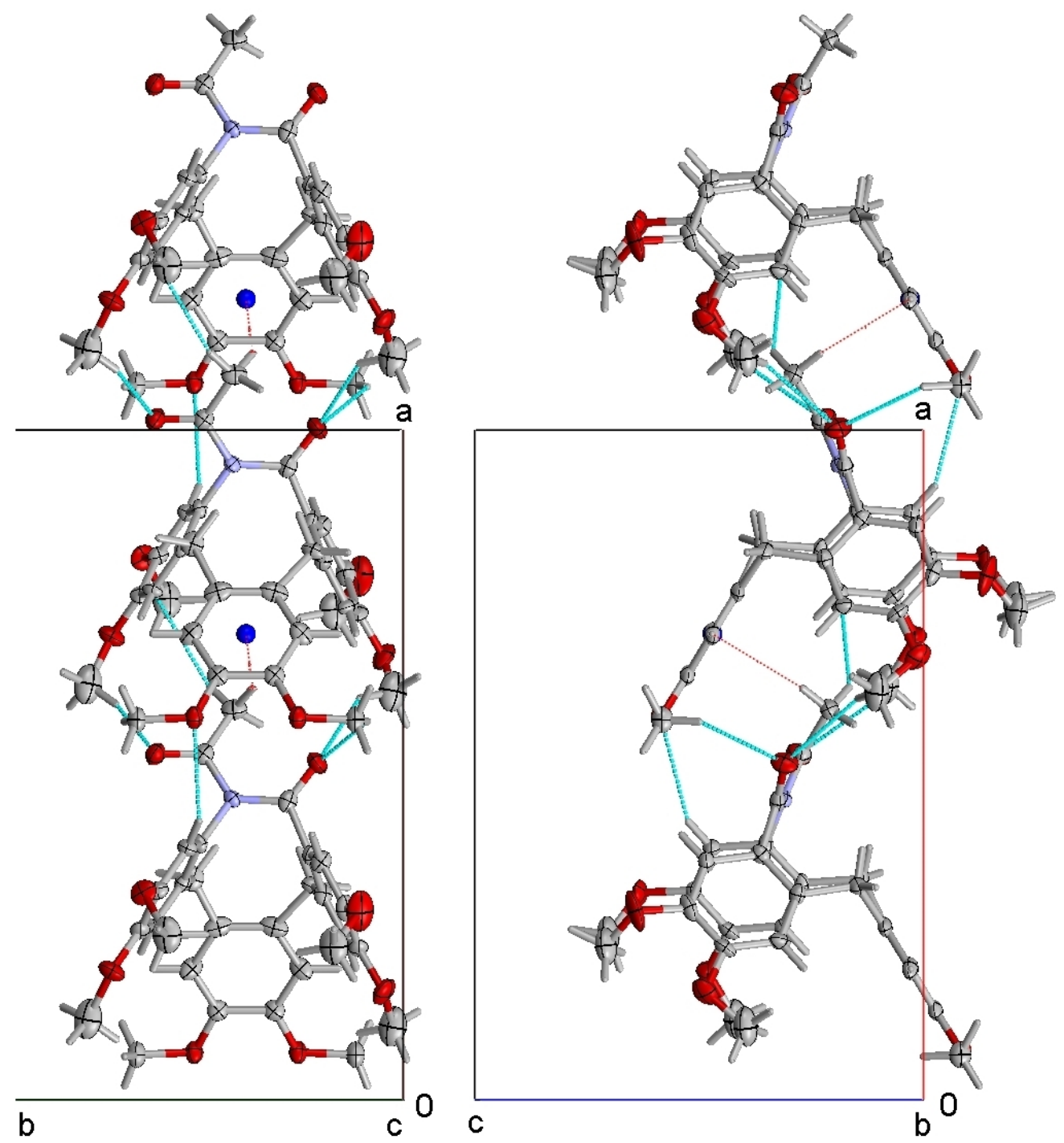

Table 1 Experimental table

5-Acetyl-2,3,8,9,13,14-hexamethoxy-11,16dihydrotribenzo[b,e,h]azecin-6(5H)-one

Crystal data

Chemical formula

$\mathrm{C}_{29} \mathrm{H}_{31} \mathrm{NO}_{8} . \mathrm{CHCl}_{3}$

$M_{r}$

640.92

Cell setting, space group

Orthorhombic, Pnma

Temperature $(\mathrm{K})$

100 (2)

$a, b, c(\AA)$

16.7247 (18), 15.7070 (16), 11.2154 (11)

$V\left(\AA^{3}\right)$

$2946.2(5)$

Z

4

$D_{x}\left(\mathrm{Mg} \mathrm{m}^{-3}\right)$

1.445

Radiation type

Mo $K \alpha$ 
$\mu\left(\mathrm{mm}^{-1}\right)$

Crystal form, colour

Crystal size (mm)

Data collection

Diffractometer

Data collection method

Absorption correction

$$
\begin{aligned}
& T_{\min } \\
& T_{\max }
\end{aligned}
$$

No. of measured, independent and observed reflections

Criterion for observed reflections

$R_{\text {int }}$

$\theta_{\max }\left({ }^{\circ}\right)$

\section{Refinement}

Refinement on

$R\left[F^{2}>2 \sigma\left(F^{2}\right)\right], w R\left(F^{2}\right), S$

No. of relections

No. of parameters

$\mathrm{H}$-atom treatment

Weighting scheme

$(\Delta / \sigma)_{\max }$

$\Delta \rho_{\max }, \Delta \rho_{\min }\left(\mathrm{e} \AA^{-3}\right)$
0.36

Plate, yellow

$0.60 \times 0.60 \times 0.27$

Bruker AXS SMART APEX CCD diffractometer

$\omega$ scans

Multi-scan (based on symmetry-related measurements)

0.768

0.906

19031, 3783, 2924

$I>2 \sigma(I)$

0.031

28.3

$F^{2}$

$0.077,0.222,1.04$

3783 reflections

310

Constrained to parent site

Calculated $w=1 /\left[\sigma^{2}\left(F_{o}^{2}\right)+(0.0991 P)^{2}+\right.$ 5.3522P] where $P=\left(F_{o}^{2}+2 F_{c}^{2}\right) / 3$

$<0.0001$

$0.96,-0.95$

Computer programs: Apex2 v2.1-4 (Bruker, 2007); SHELXTL 6.14 (Bruker, 2000-2003; Sheldrick, G. M., 2008).

\begin{tabular}{|c|c|c|c|c|}
\hline$D-\mathrm{H} \cdots A$ & $D-\mathrm{H}$ & $\mathrm{H} \cdots A$ & $D \cdots A$ & $D-\mathrm{H} \cdots A$ \\
\hline $\mathrm{C} 3 \mathrm{~A}-\mathrm{H} 3 \mathrm{~A} \cdots \mathrm{O} 3^{\mathrm{ii}}$ & 0.95 & 2.67 & $3.497(8)$ & 146 \\
\hline $\mathrm{C} 18-\mathrm{H} 18 \mathrm{C} \cdots \mathrm{C}^{2} \mathrm{~A}^{\mathrm{iii}}$ & 0.98 & 2.79 & $3.606(13)$ & 141 \\
\hline $\mathrm{C} 15-\mathrm{H} 15 \cdots \mathrm{O} 3^{\text {iv }}$ & 1.00 & 2.35 & $3.220(4)$ & 145 \\
\hline $\mathrm{C} 12 \mathrm{~A}-\mathrm{H} 12 \mathrm{D} \cdots \mathrm{O} 2 \mathrm{~A}$ & 0.98 & 2.40 & $2.968(19)$ & 116 \\
\hline $\mathrm{C} 18-\mathrm{H} 18 \mathrm{~A} \cdots \mathrm{Cg}^{\mathrm{v}}$ & 0.98 & 2.63 & 3.496 & 148 \\
\hline $\mathrm{C} 14-\mathrm{H} 14 \mathrm{~A} \cdots \mathrm{O} 4^{\mathrm{vi}}$ & 0.98 & 2.68 & $3.381(7)$ & 129 \\
\hline $\mathrm{C} 13 \mathrm{~A}-\mathrm{H} 13 \mathrm{E} \cdots \mathrm{O}^{\mathrm{vi}}$ & 0.98 & 2.36 & $3.271(14)$ & 155 \\
\hline $\mathrm{C} 13-\mathrm{H} 13 \mathrm{C} \cdots \mathrm{O} 4^{\mathrm{vi}}$ & 0.98 & 2.65 & $3.466(14)$ & 141 \\
\hline
\end{tabular}

Table $2 \mathrm{C}-\mathrm{H} \cdots \mathrm{O}$ intermolecular interactions $\left(\AA,{ }^{\circ}\right)$ 
Selected $C-H \cdots \mathrm{O}$ bonds in the alternative (not realized) setting with enantiopure chains along a

\begin{tabular}{ccccc}
\hline$D-\mathrm{H} \cdots A$ & $D-\mathrm{H}$ & $\mathrm{H} \cdots A$ & $D \cdots A$ & $D-\mathrm{H} \cdots A$ \\
\hline $\mathrm{C} 13 \mathrm{~A}-\mathrm{H} 13 \mathrm{E} \cdots \mathrm{O} 4^{\text {vii }}$ & 0.98 & 2.95 & $3.880(13)$ & 159 \\
\hline $\mathrm{C} 13-\mathrm{H} 13 \mathrm{C} \cdots \mathrm{O}^{\text {vii }}$ & 0.98 & 2.10 & $2.862(15)$ & 133 \\
\hline
\end{tabular}

Symmetry codes: (i) $x, 1 / 2-y, z$, (ii) $x+1 / 2,-y+1 / 2,-z+1 / 2$; (iii) $x+1 / 2, y,-z+1 / 2$; (iv) $x+1 / 2, y,-z+3 / 2$; (v) $-x, y+1 / 2,-z$; (vi) $x-1 / 2, y,-z+1 / 2$; (vii) $x-1 / 2,-y+1 / 2,-z+1 / 2$. Ring centroid $\mathrm{Cg} 1$ based on the atoms $\mathrm{C} 9, \mathrm{C} 10, \mathrm{C} 11, \mathrm{C} 9^{\mathrm{i}}, \mathrm{C} 10^{\mathrm{i}}, \mathrm{C} 11^{\mathrm{i}}$

Acknowledgements The diffractometer was funded by NSF grant 0087210 , by Ohio Board of Regents grant CAP-491, and by YSU. NSF Grant DBI-0216630 is gratefully acknowledged for the Varian UNITY-300 NMR obtained through the NSF Major Instrumentation Program. We gratefully acknowledge Mr. Calvin Austin of Youngstown State University for collection of DSC and TGA data.

\section{References}

Ahmad, R. \& Hardie, M. J. (2006). Supramol. Chem. 18, 29-38.

Barabas, O., Menyhard, D. K., Bocskei, Z., Simon, K., Kiss-Ajzert, I., Takacs, K. \& Hermecz, I. (2000). Tetrahedron: Asymmetry 11, 4061-4070.

Burlinson, N. E. \& Ripmeester, J. A. (1984). Journal of Inclusion Phenomena 1, 403-409.

Bruker (2007). Apex2 v2.1-4. Bruker AXS Inc, Madison (WI), USA.

Bruker (2000--2003). SHELXTL 6.14. Bruker AXS Inc, Madison (WI), USA.

Chion, B., Lajzerowicz, J., Bordeaux, D., Collet, A. \& Jacques, J. (1978). J. Phys. Chem. 82, 26822688.

Collet, A. (1987). Tetrahedron 43, 5725-5759.

Collet, A. (1996). Comprehensive Supramolecular Chemistry. In Atwood, J. L., Davies, J. E. D., MacNicol, D. D., Vögtle, F. \& Lehn, J. M., Eds.; Vol. 6, pp 281-303, Pergamon: Oxford, U.K., .

Hardie, J. J., Mills, R. M., \& Sumby, C. J. (2004). Org. Biomol. Chem. 2, 2958-2964.

Huang, J., Chen, S., Guzei, I. A. \& Yu, L. (2006). J. Am. Chem. Soc. 128, 11985-11992.

Hyatt, J. A., Duesler, D. Y., Curtin, D. Y. \& Paul, I. C. (1980). J. Org. Chem. 45, 5074-5079.

Jacques, J.; Collet, A.; Wilen, S. H. (1981). Enantiomers, Racemates and Resolutions; John Wiley and Sons: New York, 1981, (reprint edition 1991, reissued with corrections, Krieger Publishing Co.:

Malabar, FL, 1994).

Kato, T., Mizoshita, N., \& Kishimoto, K. (2006). Angew. Chem. Int. Ed. 45, 38- 68, and references cited therein

Kondepudi, D. K. \& Crook, K. E. (2005). Crystal Growth \& Design 5, 2173-2179.

Lutz Jr., M. R., French, D. C., Rehage, P. \& Becker, D. P. (2007a). Tetrahedron Lett. 48, 6368-6371.

Lutz, M. R., Jr., Zeller, M. \& Becker, D. P. (2007b). Acta Cryst. E 63, o3857-o3858.

Lutz, M. R., Jr., Zeller, M. \& Becker, D. P. (2008). Tetrahedron Lett. 49, 5003-5005.

Sawamuru, M., Kawai, K., Matsuo, Y., Kanie, K., Kato, T. \& Nakamura, E. (2002). Nature (London) 419, 702-705. 
Sheldrick, G. M. (2008). Acta Cryst. A64, 112-122.

Steed, J. W., Zhang, H. \& Atwood, J. L. (1996). Supramolecular Chemistry 7, 37-45.

Yamato, T., Sakaue, N., Tanaka, K. \& Tsuzuki, H. (2001). New Journal of Chemistry 25, 434-439.

Vande Velde, C. M. L., Chen, L. J., Baeke, J. K., Moens, M., Dieltiens, P., Geise, H. J., Zeller, M., Hunter, A. D. \& Blockhuys, F. (2004). Crystal Growth \& Design 4, 823-830 .

Zimmermann, H., Tolstoy, P., Limbach, H.-H., Poupko, R. \& Luz, Z. (2004). J. Phys. Chem. B 108, $18772-18778$. 